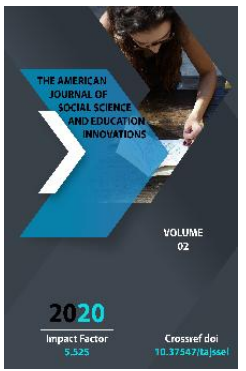

\title{
Dialogue In The Activity Of Spiritual Promoter And Its Features Of Speech Ethics
}

\author{
Irodakhon Shokhitbekovna Akhmedova \\ Basic Doctorate Student Of Andizhan State University, Andizhan Region, Republic of \\ Uzbekistan
}

Journal Website:

http://usajournalshub.c

om/index,php/tajssei

Copyright: Original

content from this work

may be used under the

terms of the creative

commons attributes

4.0 licence.

\section{ABSTRACT}

The article examines the essence of dialogue as a means of organizing mutually beneficial cooperation, comprehending the truth, its role in the activities of a propagandist of spirituality, the factor of understanding and comprehending various processes occurring in the social space.

\section{KEYWORDS}

Dialogue, conversation, spirituality, propaganda, spirituality promoter, conversation, dialogue technique, social processes, understanding, explanation.

\section{INTRODUCTION}

Historical experience in the XXI century shows that the security, stability and development of a state, a nation, its future depends in many respects on the level of potential and ability to recognize the threat to the nation. This puts enormous tasks before the propagandists of spirituality as the most educated strata of society. It is they who, in their spiritual and enlightenment activities, propagandize, expose the factors that threaten the stability of our society to the population, especially the youth. This requires them to acquire qualities such as high speaking skills, speech and conversation etiquette in the process of conducting advocacy work. In this process, dialogue and careful mastery of the requirements for it is one of the factors that ensure the success of the work of the propagandist of spirituality.

Dialogue plays an important role in social cognition (interview, conversation). It is well known that dialogue has been popular since ancient times as a literary form used to express problems using dialectics (Socrates and Plato elevated it to the level of a higher form). When talking about dialogue, it is 
necessary to mention the works of Nikolai Kuzansky, Galileo's “Dialogue on the two main systems of the world - Ptolemy and Copernicus", the humanistic culture of the Renaissance and Gadamer's "question-answer method".

In Greek translation, dialogue means a conversation between two or more persons, a form of oral communication between them that can be recorded in writing. Dialogue is a form of interaction that is complex, rich in colorful content, and inextricably linked to understanding. In dialogue, two natural human aspirations are realized: the ability to speak and hear oneself, and the desire to understand and comprehend [1].

\section{LITERATURE REVIEW}

Understanding the essence of dialogue as a means of establishing mutually beneficial cooperation, as a means of understanding the truth, is reflected in the Chinese written source "Book of Other Changes" [2], the ancient written source of India Rigvedalar, the oldest sources of Central Asia such as Avesto. In particular, the idea of "Good thought, good word, good deed" in the book "Avesto" [3] indicates the need to ensure the balance of thought, word and deed in the organization of interpersonal dialogue. Eastern and Western thinkers such as Socrates [4], Plato [5], Aristotle [6], A. Augustine [7], al-Farabi [8], Hussein Waiz Kashifi [9] and others also shared valuable ideas about the role of dialogue in social life those who put forward. Al-Farabi's idea that "People will need to unite in community and society in order to meet their needs and perfection" [10] reflects not only man's aspiration for man, but also his desire to share his thoughts and ideas with others. According to J. Rumi, "The word is the fruit of the tree of deeds. Because he is born in practice. Almighty God creates the universe with words. "[11]. The importance of words in dialogue is revealed. A. Fitrat's opinion that "..... if you do your work in consultation, then you will be better on the surface than on the ground, that is, you will have the right to live, to live" [12] is based on the possibility of reconciliation through dialogue.

The fact that dialogue is the basis of the method of dialectical thinking is reflected in the research of such scientists as V.S. Bibler, M. Buber, M. Bakhtin, N.O. Lossky, K. Popper, S. Frank and O.E. Schultz [13]. According to S. Frank, in the relationship between "l" and "you" "before any cognition there is an exchange of some interaction or behavioral activity" [14]. In this view, an attempt is made to explain the complexity of the dialogue that takes place between the "I" and the "You", an attempt to maintain their duration and dynamics. M. Bakhtin, on the other hand, analyzed the large, medium and small forms of dialogue by shaping the structural aspect of dialogue [15]. This shows that the duration of the dialogue depends on the level of complexity of the situation.

Ontological, epistemological, epistemological and socio-cultural features of dialogue, its importance as a factor in understanding and explaining social relations V.I. Arshinov, L. Batkin, E.N. Popov, T.S. Shikina. It has been extensively studied in the writings of scholars such as Abd al-Latif. In particular, according to E.N. Popov, "Today, in the world, dialogue is becoming an increasingly popular form of communication in various fields of human activity, and the study of its ontological aspects is important" [17]. After all, dialogue with society serves to preserve humanity as a 
single organism. At the same time, dialogue can help solve problems that arise at the socio-natural and interplanetary levels. Uzbek philosophers such as O.Fayzullaev, K.H.Honazarov, Y.Iskhakov, B.Turaev, B.Karimov, M.Sh.Sharipov, D.I.Fayzikhodjaeva, N.A.Shermukhamedova paid attention to the study of philosophical aspects of dialogue. In particular, although dialogue is not a separate subject of B. Turaev's scientific research, in his works there are ideas about communication and dialogue [18]. According to $\mathrm{N}$. Shermukhamedova, "mutual understanding of subjects takes place in dialogue" [19]. This means that in any situation, the joint conversation of two or more people is the main means of organizing social relations.

\section{RESEARCH METHODOLOGY}

In the course of the research were used scientifically-philosophical principles and methods such as systematics, theoreticaldeductive conclusions, analysis and synthesis, history and logic, hermeneutic analysis, inheritance, universalism and nationality, comparative analysis.

\section{ANALYSIS AND RESULTS}

On the virtues of the art of oratory and the qualities seen in it, Beruni writes: “... let us take this eloquence in the Arabic language. If asked about his interest, it is a virtue of his own kind, about which the Prophet (peace and blessings of Allaah be upon him) said, "Indeed, there is magical power in speech". Due to the existence of puberty, the weakness of the Qur'an, which is the essence of Islam and faith, is proven. With its help, some people benefit from others. "[20] These views of Beruni testify to the importance of the art of public speaking in the countries of the
Middle East, including Central Asia. Issues related to the theoretical aspects and practical application of the art of oratory are described in detail in the logical teachings of al-Farabi, Ibn Sina and Abu Abdullah al-Khwarizmi. Abu Abdullah al-Khwarizmi correctly describes rhetoric as the "art of oratory".

Hussein Waiz Kashifi outlines the rules that must be followed in the process of understanding and explaining the participants during the dialogue. "It is known that a person who does not follow the noble speech of man and does not follow the etiquette of speech is deprived of this honor. The word should always be used for merit, be accurate and truthful. If not, it is better to remain silent. There are a number of conversational etiquettes that need to be followed, both for sheikhs and those who have achieved other careers, and for those who have not yet reached a career, as well as for murids. What rules should career followers follow in a conversation; First, let everyone say the right word, depending on their situation. Second, let him speak with kindness and gentleness, without being rude. Third, let him smile and speak openly as he speaks. Fourth, he should not raise his voice and speak in a way that does not bother the listeners. Fifth, let him say meaningful things that will benefit people. Sixthly, if the word has no value, it should not be mentioned, because the word of the great is like a seed, and if the seed is empty or rotten, it will not germinate wherever you sow it."[22]. This means that direct dialogue requires mutual respect for the dialogue to be meaningful and meaningful. The disappearance of this mutual respect for today is an expression of the loss of the culture of reading in our society. 
Indeed, because of the high ability to debate in the Middle Ages, the scholars of that period sometimes argued for several days, which served as an opportunity to determine the level of knowledge of the thinkers. University students were specially prepared for such discussions, and simple practical exercises consisted of regular exercises and repetition of texts. The text has a "changing" nature, that is, the events underlying the plot are dynamically alternating [23]. This is achieved through constant dialogue with the reader and continuous creation of meaning and content. For example, in German universities, additional classes took the form of a conversation between $a$ teacher and a student, in which the teacher asked the student questions and forced the student to answer them. Of course, this process is designed to identify the shallow aspects of the knowledge in it. Such public debates were held weekly.

When thinking about the importance of dialogue in socio-cultural relations, in the activities of spiritual propagandists, we must first pay attention to the art of debate. In this sense, the German scientist Schwittall cites four methods that need to be known in order to carry out a dialogue.

A. At least two individuals can be identified as participants in the communicative exchange process.

B. These individuals are supposed to be in a process of 'interaction', i.e. their views are focused on each other.

C. In this exchange process, the function of dialogue is performed by a separate system of signs in the process of mutual speech.
D. The duties of speaker and listener pass from one participant to another in turn [24].

In our opinion, while these views of the author seem perfect at first glance, they do not provide for the level of knowledge of the participants. In this process, the function of dialogue aimed at acquiring knowledge fails. In our view, dialogue is the connection of people who are firm in their opinions in a logical communicative process. Dialogue also demonstrates the adaptation of language to a clear and specific environment.

In the process of spiritual propaganda, the participants of the dialogue do not lose anything, but are identified in the information in the exchange of ideas, and spiritual growth is manifested in exchange for new knowledge. The more meaningful the dialogue, the deeper its participants will think. Their creative abilities develop dynamically, and as a result of their actions, the world falls into a new meaningful mold. Even when the participants of the dialogue contradict each other, they retain their spiritual and intellectual qualities. Dialogue is the cheapest and fastest form of information exchange.

It is important to note that the world today is more controversial and controversial than ever. A meaningful, effective and promising dialogue in various spheres of socio-cultural life can be observed in science and politics, in the relations of parties and nations, peoples and governments. Dialogue based on logical forms of creative thinking plays an important role in the future acceleration of social development in our time. Good dialogue is in many ways an example of what we envision in a democracy and civil society. Political meetings and debates show that tension and 
rudeness in the process of speaking, noncompliance with the usual moral norms, inability to reach the essence of ideas, insecurity, eliminate the opportunity to fully express their potential. Therefore, an in-depth study of the culture of dialogue is necessary for everyone.

It is not enough to have a high class or prestige in terms of social background, career, level of intelligence to think meaningfully. The fact that a person's state of inference culture is well-formed, audible, and achieves hearing is a testament to his or her secular and local knowledge.

Nowadays, dialogue participants also resort to forms of dialogue that allow them to find solutions to problematic situations. For example, the generalization of different forms of dialogue in a modern speech provides ample opportunity to draw a holistic conclusion.

The roots of dialogism are hidden in its function in expressing human speech culture. Through speech, one person not only provides information to another, but also forms a system of cultural communication. Get rid of this unimportant view of data speech. According to B.F. Porshnev, the main function of speech is its domination, subjugation or resistance [25]. This is why we can also see speech as a whole based on dry and insensitive factors based on the final conclusion. It can also occur in a state of affirmation or denial and other types of expression, hesitation and questioning.

We can explain the result of the dialogue by the fact that its forms achieve the intended purpose. It would be simplistic to understand and assimilate the ideas contained in the public speeches based on command and threat threats. Experience shows that even a simple exchange of information is ineffective. In contrast to this situation, the interestingness of departmental, trusting dialogue allows participants to achieve a high level of positive outcomes with value.

Logically, the concept of dialogue is a meeting of different subjective worlds, different concepts related to a common situation or subject. What matters to people is not what they say, but how they approach the issue. Therefore, during the conversation, the speech should be enriched with clear and valuable information from the point of view of the speaker, to the extent that it attracts the attention of the participants. An insensitive, illogical explanation usually disrupts the listener's attitude, leading to the dialogue process ending in vain.

In the dialogue process, an individual's opinion depends on his or her assessment by the listener on the basis of political, ethical, and other aspects of the topic of communication. The interpretation of new ideas and feelings, the consensus of all dialogue participants, the process of communication is always an expression of cooperation. The situations in which the dialogue takes place are different in nature. Depending on the situation, a person may approve, supplement, or doubt the views of the dialogue participant. In such a situation, the dialogue participants are required to "clarify the relationship".

Speaker-listener dialogue is a form of attitude that is organized and focused on the development of the socio-cultural factor in a comprehensible form on certain questions. In terms of form and function, it is a concept close to reporting, reporting, reporting. The 
dialogue is manifested in the form of a survey according to its wide distribution, for example the dialogue can be in the form of a social survey such as a questionnaire, an interview. The dialogue allows you to get some information from the person being interviewed.

Conversation and discussion is a more common form of dialogue. During the conversation, the participants discuss some things, exchange ideas and gain new information on the topic of conversation. However, the benefits of such an exchange are limited, with participants using concepts that meet each other's needs in the first place. In such a discussion, there is a conflict of views, opinions, participants approve their opinion based on their own worldview, criticize the views of the other party.

In general, dialogue is a necessary type of verbal communication, the form of which is multifaceted, universal in terms of understanding and explanation. The idea of "model structure" put forward by German logicians P. Lorentsen and K. Lorentz about the structure of dialogue is of conceptual significance. Based on this method, we will be able to know the following formal terms of the dialogue;

in the dialogue, the process of "thinking" is carried out by the participants in turn;

the dialogue ends with a completed result stating who has won and who has lost;

the participants of the dialogue shall use the means specified in the rules of discussion and the means by which they can influence its structure; dialogue begins with a process that forces the other party to interact [26];

In our opinion, the above method simplifies and simplifies the essence of the dialogue process. It ignores a large number of sets of ideas and team communication. In short, different dialogue situations are a generalization of questions and answers. After all, the dialogue itself and its outcome depend on whether the responses to its successful or unsuccessful completion are structured in an orderly or disordered, meaningful or meaningless manner.

In order to carry out the dialogue, the spirituality facilitator must clarify the initial data of its participants, as well as the information about the inequality in the knowledge of the participants. Each new phrase is also new information for the interlocutor.

Each dialogue consists of a specific thought structure:

a) question - answer;

b) a phrase - an expression of consent or protest;

c) assertion - consent or suspicion;

d) information - question;

e) request- readiness to do or not to do it.

The analysis of the content of the dialogue begins with the interaction of question and answer, the main part of which.

One of the main conditions for a dialogue by a spiritual propagandist is that there is a desire and need for communication between the participants in the conversation. Language can unite people, it can also be a common topic for their conversations, but the personal characteristics of the participants can prevent 
the conversation from taking place. Interviewees are usually selected from willing people with clear personal characteristics.

A productive conversation is not a competition, but a collaboration, it is like a beautiful and harmonious dance. Collaboration in a conversation requires the participants to adhere to the rules of politeness, in addition to the pursuit of truth, the ability to think.

Dialogue is the primary, natural form of the means of verbal communication. It is therefore common in oral speech as a form of speech. But it is also presented in a scientific, journalistic, and formal bureaucratic style.

As a means of verbal communication, dialogue manifests itself as spontaneous speech. The structural structure of dialogic speech is characterized by simple sentences, brevity of thought. At the same time, the following can also be properties of dialogue.

a) the situation depends on the environment in which the conversation takes place and the interaction of the dialogue participants.

b) contextuality, which means that the idea depends on the previous idea.

c) for the interlocutors, the general spirit of the situation is the spirit of the community.

d) thought speech and non-speech-related situations - external influences.

e) involuntary, unintentional organization insomnia.

For dialogue, first of all, it is necessary to know the level of knowledge of its participants, and secondly, to know the minimum difference in their knowledge. Otherwise, the dialogue participants will not provide each other with new information on the topic of conversation, as a result of which the dialogue will not be meaningful and productive.

\section{CONCLUSION}

In the mega-civilization stage of development, there is a growing focus on the "human factor". The world, as well as in Uzbekistan, is clearly visible in all spheres of social life. This is reflected in the fact that 2017 is called the "Year of dialogue with the people and the interests of man" and a consistent activity is organized on the basis of a special state program.

Dialogue the civilized approach to the history of mankind allows us to distinguish between the commonality, originality and uniqueness of the history of each country and world history, to fully understand the place and role of the peoples of our country in world history.

Understanding social relations through dialogue is necessary for a deeper understanding of the essence of the radical changes taking place in the life of our society today, to see the future, to understand the mentality of our people and to adapt it to the requirements of the time. Based on the analysis, we came to the conclusion that the study of the history of the formation of dialogue, based on dialogue - a characteristic of human existence, in which knowledge is the main criterion.

The problem of dialogue is becoming more and more important in the way of understanding the "other", in the context of serious regional and inter-ethnic conflicts. 


\section{REFERENCES}

1. Shermukhamedova N.A. Understanding and explanation // Methodology of scientific research.Tashkent: Science and technology, 2014.-439 p.

2. Shchuchky Yu.K. Chinese Classical Book of Changes. Moscow : Science. Publishing firm "Eastern Literature". 629 p. ISBN: 5-02-017385-1

3. Avesto. Mahkamov A. translation. Tashkent: Shark, 2001.-180 p.

4. Antique rhetoric. Collection of texts, articles, comments. and general ed. A.Takho-Godi. Ser: University Library. Moscow: Moscow State University, 1978.237-285 p.

5. Platon. Dialogues: Protagoras, Big Ippius, Ippius the Lesser, Euthydemus, Euthyphron, Apology of Socrates. Moscow: Academic project, 2011 - 351 p.

6. Aristotle Rhetoric. Poetics. -Moscow: Labyrinth, 2011.-208 p .

7. Augustine Aurelius the Blessed. About the Christian struggle. - Moscow: TsBPI, 2010 . 133 p.

8. Abu Nasr Farobi. A word about the need of people to unite and help each other // City of noble people.Tashkent: New Century Generation, 2016. - 238 p .;

9. Kashifi Hussein Waz. Futuvvatnomai sultan. Morals are special. -Tashkent .: Scientific Publishing House "National Encyclopedia of Uzbekistan". 2011;

10. Abu Nasr al-Faroobi. A word about the need of people to unite and help each other // City of noble people.Tashkent: New Century Generation, 2016. - $238 \mathrm{p}$.
11. Rumiy J. Ichindagi ichindadur.Tashkent: New Century Generation, 2013. - $91 \mathrm{p}$.

12. Fitrat A. Karam // Selected works.Tashkent: Ma'naviyat, 2010. -135 p.

13. Shultz OE Practice of Socratic dialogue in dianalysis // Psychotherapy, practical and counseling psychology - the interweaving of destinies: Materials of the International Congress. - Kiev. October 4-7, 2012 // Monthly scientific and practical journal Psychotherapy. Moscow, 2012.- No. 12.- 99-100 p.

14. Frank S.A. Compositions. Series: Classical philosophical thought. Minsk: Harvest, 2000.-352 p.

15. Bakhtin M.M. Collected Works. T.6."Problems of Dostoevsky's Poetics", 1963. Works of the 1960s 1970s. - Moscow: Publishing house "Russian dictionaries", "Languages of Slavic culture", 2002. -302-303 p.

16. Abd al-Latif K. Qiraat fi-l-falsafa alarabiyya al-muasira. Beirut. Dar at talia. 1994. $-55 \mathrm{~s}$.

17. Popov E.N. Ontological aspects of dialogue and dialogical relations in the modern world 09.00.01 / Popov E.N. (Place of protection: North-Eastern Federal University named after M.K. Ammosov) .- Yakutsk, 2012. -23 p.

18. Turaev B.O. Social philosophy, sociology, national idea and journalism. Selected works 2 volumes. Tashkent. Publishing house of the National Library of Uzbekistan named after A.Navoi, 2015. -360 p.

19. Shermukhamedova N.A. Understanding and explanation // Methodology of scientific research.- 
Tashkent: Science and technology, 2014.-439 p.

20. Abu Rayhon Beruni. Geodesy // Materials on the history of progressive socially-philosophical thought in Uzbekistan. -Tashkent: AS, 1976. -203 p.

21. Fayzikhojaeva D.I. Central Asian thinkers on argumentation./Dialogue of philosophical cultures. A collection of scientific articles. -Tashkent: Nishon -Noshir, 2014. -139 p.

22. Discovery Hussein Preacher. Futuvvatnomai sultan. Tashkent. State Scientific Publishing House "National Encyclopedia of Uzbekistan". 2011. -71 p.

23. Xolbekov M.N. Landscapes of modern literature of the twentieth century. Collection of articles. - Tashkent: Mumtoz Suz Publishing House, 2013. p.373.

24. Schwitalla J. Kommunikative Stilistik zweier sozialer Welten in MannheimVogelstang. Berlin, -New York: de Gruyter, 1995.-558 s.

25. Porshnev B.F. About the beginning of human history (problems of paleopsychology) / Scientific. ed. O. T. Vite. - St. Petersburg: Aleteya, 2007.$720 \mathrm{p}$.

26. Lorenz K. Dialogspiele als semantische Grundlage von Logikkalkulen//Archiv fur Math. Logik und Grundlagenforschung.1968. 11, 32-55, 73-100 pp. 